\title{
ECO-TRAILS - AN OPPORTUNITY FOR LEARNING OUTDOORS CLOSE TO NATURE
}

\author{
Krasimir Todorov ${ }^{1}$, Slaveya Petrova ${ }^{2}$, Bogdan Nikolov ${ }^{3}$, \\ Ivanka Dimitrova-Dyulgerova ${ }^{4}$, Delka Karagyozova-Dilkova ${ }^{5}$
}

\begin{abstract}
Acquiring key competences is a priority in contemporary education. According to some authors, ecotrails provide an opportunity for training in natural ecosystems. The purpose of this study is to examine the capabilities of a constructivist design for learning that is close to nature with respect to acquiring practical knowledge, motivation, and formation of environmental competencies in students. To verify this assumption, the following methods were applied: curricula analyses of teaching biology in secondary schools (Grades 5-8, Ministry of Education and Science of Bulgaria) and high schools (Grades 9-10, Ministry of Education and Science of Bulgaria), and pedagogical experiments and surveys among students for approbation of a model for environmental education that is close to nature. A syllabus for selectable (optional) training on ecological topics was developed. A model of ecological training, "close to nature", was devised through the constructivist design and active approach, and in approbation of the model, students acquired practical knowledge, formed environmental competencies, and an increase in their motivation to protect the ecological balance.
\end{abstract}

UDC Classifications: 57.08 DOI: http://dx.doi.org/10.12955/cbup.v4.798

Keywords: eco-trails, experiential, education, syllabus.

\section{Introduction}

Acquiring key competences is a priority in modern education, which is set according to the requirements of the European Framework of Reference. At the end of compulsory education, young people should have acquired key competences to a level that prepares them for adult life and provides a basis for further training and advancement in their professional lives. Competence in natural science refers to the ability and desire to exploit knowledge and methods through which nature can be explained, questions are asked, and answers are provided based on evidence. This competence also includes understanding the changes caused by human activity and one's sense of responsibility as an individual citizen. According to some authors (Angelova, 2008; Kostova, 2013), formation of natural science competence becomes more effective with training that is close to nature. According to Kostova (2013), studying the natural ecosystems through "reading the book of nature" can help students understand the factual situation with environmental problems caused by negative human impact.

An eco-trail is a relatively safe area in nature, which provides a variety of natural conditions for studying relationships and interactions between organisms in a natural environment. The preliminary exploration of a place where an eco-trail passes allows the teacher to become aware of its biological diversity, and to plan efficient activities for students. According to Kolb's theory (Kolb, 1984, p.38), "learning is a process that creates knowledge through transformation of experience". Kolb (1984) also considered learning is a cyclic process, consisting of four stages:

- concrete experience, knowledge, and skills achieved (experience);

- reflective observation (thinking);

- abstract conceptualization (generalization);

- active experience, experimentation, practical application (planning a new activity).

\footnotetext{
${ }^{1}$ Krasimir Todorov, University of Plovdiv "Paisii Hilendarski", Faculty of Biology, Department of Botany and Methods of Teaching in Biology, 24 Tzar Assen Str., 4000, Plovdiv, Bulgaria, krasi1_m1@abv.bg

${ }^{2}$ Slaveya Petrova, University of Plovdiv "Paisii Hilendarski", Faculty on Biology, Department of Ecology and Environmental Conservation, 24 Tzar Assen Str., 4000, Plovdiv, Bulgaria

${ }^{3}$ Bogdan Nikolov, University of Plovdiv "Paisii Hilendarski”, Faculty on Biology, Department of Ecology and Environmental Conservation, 24 Tzar Assen Str., 4000, Plovdiv, Bulgaria

${ }^{4}$ Ivanka Dimitrova-Dyulgerova, University of Plovdiv "Paisii Hilendarski", Faculty of Biology, Department of Botany and Methods of Teaching in Biology, 24 Tzar Assen Str., 4000, Plovdiv, Bulgaria

${ }^{5}$ Delka Karagyozova-Dilkova, University of Plovdiv "Paisii Hilendarski", Faculty of Biology, Department of Botany and Methods of Teaching in Biology, 24 Tzar Assen Str., 4000, Plovdiv, Bulgaria
} 
In our view, training in a natural ecosystem will be highly successful if it is based on constructivism, active approach, and active learning. For that reason, this study aims to design a constructivist methodological model for gaining environmental competencies in students based on learning environmental issues outdoors, in nature.

\section{Experimental design}

The subject of the study was teaching biology at secondary schools, particularly the ecological content, and forming competencies for students regarding natural science. The study involved constructivist design and active learning in nature, as a method of teaching ecological content.

The educational experiment was based on the following working hypothesis: A training of constructivist design and active learning by Kolb's cycle (Kolb, 1984) conducted outdoors, in nature (along eco-trails), will lead students to acquiring practical knowledge, motivation, and ecological competencies.

To check this assumption, the following methods were applied: analysis of the biology teaching curricula at secondary schools (Grades 5-8, Ministry of Education and Science of Bulgaria) and high schools (Grades 9-10, Ministry of Education and Science of Bulgaria), and an educational experiment for approbation of a model for environmental education outdoors in nature through pedagogical observation and surveys with students.

To achieve these goals and verify the working hypothesis, the following main tasks were performed:

1. Theoretical study of the research problem;

2. Analysis of the biology teaching curricula, to identify appropriate educational content for studying outdoors in nature, using an active approach;

3. Design a methodological model for learning outdoors in nature, basing on the constructivist design and active learning by Kolb's cycle;

4. Selection of criteria and indicators, and relevant diagnostic questions and tasks for reporting results of the experiment;

5. A pedagogical experiment through the resulting didactic model and analyze the results.

The experiment was held in the city of Plovdiv, Bulgaria, in the large city park, "Lauta", with students from the Professional School of Construction, Architecture, and Geodesy "Arch. Kamen Petkov", Plovdiv, during the school year 2015/2016. The study included team members of the project, "Development of a conceptual design for eco-trail construction and methodological models for ecological education in nature", granted by the Fund "Scientific researches" from the University of Plovdiv "Paisii Hilendarski".

In reporting the results, the following criteria and indicators were used for rating students:

6. Level of ecological knowledge obtained - based on ability to define and understand basic concepts related to the effects of human activity in the environment;

7. Skills acquired - based on ability to apply observations when compiling scientific data and use reasoning to interpret results;

8. Ecological competencies acquired - based on display of knowledge and compliance with rules and regulations for ecological behavior, as well as personal attitude towards the environment and willingness to participate in environmental restoration.

The tools for recording the criteria and indicators included two tests and surveys (one of each conducted before and then after the experimental training).

\section{Results and Discussion}

An analysis of curricula provided basic concepts and topics from the learning content in biology, which was appropriate for study outdoors in nature, through an activity approach. A new syllabus was developed for selectable (optional) training on ecological topics, enabling ecological education through active approach and constructivist design of learning. The topic of the syllabus was "I know and protect nature in my native land", which was a 36-hour subject based outdoors in nature. 
Based on modern theoretical psychology, pedagogy, and didactics, a methodological model was devised, using theory of constructivism. The foundations of the constructivist design of learning, applied in experimental training, were based on the philosophy of constructivism, namely that:

- Knowledge is based on the personal experience of students.

- Knowledge is individual and socially constructed.

- Problematic situations are replaced with real-life situations.

- Students use their knowledge to apply it in life.

- Inclusivity of knowledge is sought - phenomena are studied in a complex way - as they occur in reality.

- The main source of information is nature.

- The basic teaching methods applied are monitoring in a natural environment and practical work outdoors, close to nature.

- Students get to know how to find necessary information.

- Training is dialogical.

- Training is personally oriented towards students.

- The teacher encourages and facilitates students' creative searches.

- Students' mistakes are considered as additional opportunities to provoke students' thinking and understanding.

- Individual, group, and frontal-instruction arrangements of learning activities are applied.

- The emphasis in group work is focused on cooperation rather than on competition.

- The groups are heterogeneous; possibly developed in teams.

\section{Innovative Technology was Developed for Nature Observation through an Activity Approach}

Students' cognitive activity was based on the theory of learning through experience and implemented with the means of Kolb's cycle (Kolb, 1984). There were many opportunities for creativity and expression of teachers and students' personal qualities. The methodological model included tasks for activity-related learning and each task was performed in small groups (4-5 students). The results were shared and discussed among all participants. The tasks for investigating each key concept were divided into four stages and arranged in a system that follows Kolb's cycle of learning (experience, thinking, generalization, and planning a new activity). Students actively constructed their own knowledge, rather than through using prepared information.

\section{Methodological Model}

The first stage (experience) started with activities that challenged students' own experience including their experiences at sensory and emotional levels. In this stage, they performed tangible activities on individually or in groups. Mostly, they worked in small groups (4-5 students), before presenting results. The students could apply brainstorming, methods of associations and associative cloud setting (an intellectual map), a presentation of various objects, and tasks for independent work that would update their knowledge, skills and experiences.

In the second stage (thinking), new information was sought. Students analyzed what they had observed and experienced, and shared their experience from the first stage. The second stage was directed at considering (reflecting) their newly acquired experiences. Students reflected on their knowledge, as well as their actions and feelings. They mostly worked in groups or in pairs. Various types of discussions were often used as methods of deliberation. Students' abilities to ask questions and view the situation or problem from different perspectives were encouraged.

The third stage (generalization) included generalizations and formation of notions and concepts. This built upon the sensory, emotional, logical, and rational levels in assimilating new information. Intellectual maps could be developed, new concepts gained, and generalizations formulated. Generally, this stage started with students working in groups, but finished with frontal-instruction of the entire class, involving the help and support of the teacher, who did not provide ready answers but asked questions in discussion, provoking students' deductive thinking, and thus, empowering them to gain new knowledge on their own. 
Table 1: Description of the syllabus

\begin{tabular}{|c|c|}
\hline \multicolumn{2}{|c|}{ Topics } \\
\hline \multicolumn{2}{|c|}{$\begin{array}{l}\text { Establishing and acceptance of rules of conduct for working } \\
\text { outdoors, in nature. }\end{array}$} \\
\hline 1. & Investigating the abiotic factors of the environment \\
\hline $\begin{array}{l}1.1 . \\
\text { accor }\end{array}$ & $\begin{array}{l}\text { Light regime. Ecological groups of plants and animals } \\
\text { ng to light; }\end{array}$ \\
\hline 1.2. & Temperature regime. \\
\hline 1.2.1. & Plant and animal adaptations to low temperatures \\
\hline heat $\mathrm{e}$ & $\begin{array}{l}\text { Groups of animals according to their temperature and } \\
\text { change; }\end{array}$ \\
\hline $\begin{array}{l}1.3 . \\
\text { plants }\end{array}$ & $\begin{array}{l}\text { Water as an ecological factor. Ecological groups of } \\
\text { nd animals according to their needs of water }\end{array}$ \\
\hline $\begin{array}{l}1.4 . \\
\text { air } \mathrm{m}\end{array}$ & $\begin{array}{l}\text { Air as an ecological factor. Ecological significance of } \\
\text { ement }\end{array}$ \\
\hline $\begin{array}{l}1.5 . \\
\text { and th }\end{array}$ & $\begin{array}{l}\text { Soil as an ecological factor. Species of soil organisms } \\
\text { ir adaptations for living in the soil }\end{array}$ \\
\hline $\begin{array}{l}2 . \\
\text { biolog }\end{array}$ & $\begin{array}{l}\text { Investigating the adaptation of organisms and } \\
\text { cal rhythms }\end{array}$ \\
\hline
\end{tabular}

3. Investigating the biotic factors of the environment. Interrelations in populations.

4. Investigating the anthropogenic factors and their effects on the environment

5. Exploring the sources of pollution in the region. Measures for protection against pollution.

6. Identifying the population structures of some plant and animal species. Medicinal plants.

7. Establishing the composition and morphological structure of the biocenosis observed. Horizontal and vertical distribution of species. Consortia.

8. Observing and recording phenomena in secondary succession. Measures to protect the ecosystems.

9. Ethology. Behavioral ecology.

Monitoring at different levels of behavior - of an individual, a couple, a family group and population

10. Monitoring instinctive behavior in worms, insects, spiders, and birds.

11. Investigating the feeding behavior, food specialization, nutritional strategies, and hunting practices of animals. Measures to protect food from polluters and nourishment.

12. Forms of social relations. Division of labor of insects (ants). Marital and parental behavior in birds.

Planned activities

A student will be able to:

1. describe, explain and observe rules of conduct for working outdoors, in nature;

2. describe and explain regional environmental problems;

3. apply ecological knowledge to explain and solve specific problems;

\section{4. plan and conduct} observations to investigate various organisms, their adaptations and behavior, and natural phenomena;

\section{5. appropriately represent} results of observation (in tables, diagrams, drawings, etc.); and

6. assess the condition of the environment.
1. Students take temperature regime, light regime measurements, following definite instructions;

2. Students plan and perform observations on organisms' adaptations to various environmental factors;

3. Students classify the observed organisms in ecological groups;

4. Students apply various methods for investigating the environment;

5. Students plan and perform observations in a natural environment. They keep a record diary of what has been observed;

6. Students organize and participate in monitoring activities and nature conservation; and

7. Students work in a group for assessing the condition of the environment.

Source: Author 
The fourth stage (planning a new activity) concerns the practical application of new constructs (concepts) and planning for further study. Again, students could work individually, in pairs, or in groups. In this, biological experiments could be applied to prove already established deductive processes, and included monitoring, record-diary keeping, and practical work applying knowledge already gained. As an example, we present a sample student worksheet on the topic "Birds", as follows:

\section{Sample Student Worksheet}

First Stage - Experience

This starts with a discussion in which students share their own experience on the topic: Which birds have you seen in towns and villages? Describe them. Which are birds you know that inhabit settlements, and you have heard their melodious songs, but you have not seen them? Explain why nightingales are less frequently seen by people? In your answer, include their habitats, nesting, behavior and morphological characteristics.

Group work tasks:

1. Do you know these birds?

2. What gender are the sparrows in the picture? What are the distinguishing characteristics like, by which you recognized them?

3. What do you call the phenomenon in which males and females of one species have different morphological features? Explain the biological significance of sexual dimorphism. Are there birds in which males and females do not differ in morphological characteristics?

4. Describe the morphological characteristics by which you can recognize the great tit, blue tit, green woodpecker, magpie, and jay.

Second Stage - Thinking

Tasks for independent observation:

1. Analyze the chart about the number of house sparrows in the period $2005-2014$ year, and substantiate the determination about population size trends as slightly decreasing.

2. Hypothesize about possible causes for the reduction in the population.

3. What would be the consequences of the extinction of the house sparrow?

4. Give your ideas for activities in order to act against this trend.

5. Provide your personal idea about what you would do this winter to help the survival of sparrows.

Third Stage - Generalization

Implementation of the tasks is discussed, as well as the answers to the questions in the second task are commented with all students in a frontal talk. Students get to the conclusion themselves: human settlements occupy part of bird habitats; so nesting places substantially decrease. Spraying with preparations against mosquitoes and other insects in settlements greatly reduces the food of birds just in the breeding season.

These are some of the reasons for reduction in the house sparrow population. Students comment on the coexistence of humans and birds and describe the direct and indirect benefits of birds to humans. Students decide on measures to assist the survival of the birds in winter.

Fourth Stage - Planning a New Activity

Students put into practice the ideas, which they have reached to, in the third stage, namely: the need for feeding birds in winter and placement of houses for indoor-nesting birds. Places for feeders and birdhouses are discussed; an environmentally friendly way for attaching them on trees is commented. 
After installations of feeders and houses, students discuss the opportunities for monitoring their feeding, the reproductive behavior of birds and the care about their offspring. Teams for feeders loading and observation conducting are selected. The type and manner of keeping monitoring diaries are specified.

After the further activity planning, the lesson proceeds to the final stage where students share their emotions experienced during the session and the benefits of the lessons learned.

The efficiency of the didactic model developed was recorded throughout the tests and surveys.

Analysis of the empirical data from the tests and surveys showed the following:

1. Students acquired basic ecological knowledge;

2. Most students were able to apply observation in scientific data collection, but they found it difficult to use facts in decision making;

3. Almost all students showed personal attitude towards nature, but were not fully aware of human impact and interdependencies in nature. A very smaller part of them were willing to participate in environmental conservation.

The analysis showed that team work outdoors in nature, structured in the four stages of Kolb's cycle, allowed students to understand and reflect upon ecological values.

Basing on the overall theoretical and empirical analysis of the research problem, the following generalizations and conclusions are made:

1. The ecological educational content allowed organized training with constructivist design and active learning using Kolb's cycle in the outdoors in nature (along an eco-trail).

2. The experimental learning organized outdoors, in nature, led to students acquiring practical knowledge and forming ecological competencies.

3. The innovative model, established for nature observation through an active approach and selfconstruction of knowledge, led students towards positive learning, motivation, and a willingness to engage in activities for nature preservation.

\section{Conclusion}

We regard the main goal of the experiment as having been achieved. Thus, we recommend the use of the constructivist design of learning outdoors, in nature (along an eco-trail), for students to gain ecological competencies.

\section{Acknowledgements}

We are grateful to Fund "Scientific research" at the University of Plovdiv "Paisii Hilendarski" for financial support by contract SP15-BF16, managed by Assoc. prof. Delka Karagyozova-Dilkova.

\section{References}

Angelova, B. (2008). The ecological education and upbringing in third and fourth grade by means of project work, Proceedings of the anniversary scientific conference of ecology, Plovdiv, November, $1^{\text {st }}, 438-443$.

Kolb, D. (1984). Experiential Learning: Experience as the Source of Learning and Development, New Jersey, Prentice-Hall.

Kostova, Z. (2013). Project-Based Ecology Learning in Vocational Training, Journal of Environmental Science and Engineering Technology, 1, 10-22. 